16 Jones IG, Cameron D. Social class analysis-an embarrassment to epidemiology. Community Med 1984; 6 ; embarr

17 Fox AJ, Goldblatt PO. Socio-demographic mortality differentials: longitudinal study 1971-75. (OPCS Series LS differentials: longitudinal study
No 1). London: HMSO, 1982.

18 Cartwright A, Smith C. Elderly people, their medicines, and their doctors. London: Routledge, 1988.

19 Alwash R, McCarthy M. Accidents in the home among Alwash $R$, McCarthy $M$. Accidents in the home among children under 5: ethnic

20 Cartwright $\mathrm{A}$, Windsor J. Identification of people attending outpatients: congruity between hospital records and response to a postal screen. Community Med 1989; 11 225-9.

21 Butcher B. Influencing response rates-an example from the $1985 / 6$ National Travel Survey. Survey Methodology Bull 1985/6 National Travel

22 Jacoby A. Possible factors affecting response to postal questionnaires: findings from a study of general questionnaires: findings from a study of genera

23 pratit. Theres. Haskey $\mathrm{J}$. The ethnic minority populations of Great Britain estimates by ethnic group and country of birth. Population Trends 1990; 60: 35-8.

\title{
Kupio Declaration on Health Research and Human Development
}

Research on human health and health care has become increasingly common in developing countries. There is an urgent need to discuss and plan the principles of these research activities. The Society of Social Medicine in Finland and the Health Development Cooperation Group/National Agency for Welfare and Health in Finland (HEDEC) organised a conference on Health Research and Developing Countries in Kuopio, Finland, in September 1991.

The conference nominated a committee to prepare a declaration on health research and human development, which was unanimously adopted by all the participants. The declaration is reproduced below.

\section{Kuopio Declaration on Health Research and Human Development}

Health is the foundation of human development and the quality of life. Without health human and economic development is impossible. Health research is a powerful tool to enable people in diverse circumstances to apply knowledge that is already available and to generate new knowledge to tackle still unsolved problems. Health research is an investment in people-a country's most precious resource.

The overriding goal of health research is equity for women, men and children within families, communities, countries and the world. Research can achieve this goal if researchers work in partnership with the people, decision makers and their international colleagues.

To improve health and achieve equity and social justice we urge researchers and their institutions to:

* focus upon the health problems of all the people, especially the poor and disadvantaged;

* recognise the uniqueness of communities and the need for both specific and generic solutions;

* find solutions to health problems which are ethically acceptable, effective, realistic and within the means of the family, community and country; and

* share information to empower the people and their families to take responsibility for their health.

We urge each country to:

* evolve its own plan of research to achieve equity in health;

* allocate national resources to implement the research and apply the results;

* create an environment for research that will enable the country to identify its health problems, find and apply solutions and evaluate their impact, all these on an ongoing basis.

At the same time we urge all countries, in particular the industrialised countries and development assistance agencies to:

* facilitate the establishment, and support the operation of international research networks and partnerships to share information and research resources and to identify and solve global health problems;

* work with partner countries, their research institutions and their researchers to strengthen and maintain their national health research capacity;

* establish within their own countries mechanisms to promote and facilitate partnerships in health research between countries;

* provide the necesssary financial resources to support health research partnerships; and

* provide such resources on a long-term basis.

We the participants of the Conference on Health Research and Developing Countries believe that if the above recommendations are implemented, health research will make a significant contribution to health for all.

September 14, 1991.

Kuopio, Finland 